March issue of the BJGP gives only two solutions to the provision of out-of-hours care, asking doctors to take it on as a duty or to pay more for it. Perhaps one reason why some of us do not do outof-hours care is because the in-hours pay means we do not have to. Our colleagues on the continent earn far less. For many, out-of-hours pay at $£ 45$ would seem a very generous wage. Perhaps other avenues, like making it essential for revalidation, as in Holland, may make this an essential part of patient care better resourced by local doctors. Or should we hand in the towel and accept that this service cannot be provided in the face of 24-hour choice and let the 999 services take the strain (and cash)?

\section{John Sharvill,}

Balmoral Surgery, Deal, Kent.

E-mail: john.sharvill@NHS.NET

\section{REFERENCE}

1. Simpson JM, Esmail A. The UK's dysfunctional relationship with medical migrants: the Daniel Ubani case and reform of out-of-hours services. Br J Gen Pract 2011; 61(584): 208-211.

DOI: 10.3399/bjgp11X567261

\section{Revalidation}

I have just been reading Greenhalgh and Wong's very sensible article about revalidation. ${ }^{1}$ I am just about to do my first appraisal. I have looked at all the online portfolios I can find, including the NHS Appraisal Toolkit, the RCGP ePortfolio, and the new GPonline portfolio.

My problem is that they are all good for providing 'evidence', but that none of them is actually a good learning tool. I want a tool that allows me to store relevant clinical information and retrieve it again easily. A traditional computer file system is perfect for me, allowing me to subdivide into as many categories as I like, thus easily facilitating information retrieval. An ideal portfolio would allow us to prove that we've 'ticked the boxes' and would support learning by allowing easy information retrieval and by allowing the user to manipulate the system to their learning style. A system along the lines of 'Google Docs' or 'Evernote' would surely not be too hard to create. Revalidation should be about 'continuous professional development', not 'box ticking' and the eportfolios should reflect this.

\section{Louise Cockram,}

94 Queens Road, Gosport,

Hampshire, PO12 1LH.

E-mail: louisecockram@doctors.org.uk

\section{REFERENCE}

1. Greenhalgh T, Wong G. Revalidation: a critical perspective. Br J Gen Pract 2011; 61(584): 166-168.

DOI: 10.3399/bjgp11X567270

\section{Correction}

In the Back Pages article: Lasserson M. How do we learn? Br J Gen Pract 2011; 61(584): 232-233, the first paragraph: 'It was Harry Secombe who ... before I entered general practice' was included in error. The article should start with the section 'How I learnt to refer'. This has been corrected in the online version.

DOI: 10.3399/bjgp11X567289 